\title{
Prevalencia de anticuerpos séricos contra la bacteria Brucella sp. en una población humana tropical
}

\author{
Grettel Chanto ${ }^{1}$, Norman Rojas ${ }^{2}$, Adrián Ching ${ }^{1}$, Ronald Zúñiga ${ }^{3}$, Edith Castro ${ }^{4}$, Sonia Chaverri ${ }^{4}$, \\ Angelina Asenjo ${ }^{5}$ \& Elena Campos ${ }^{1 *}$ \\ 1 Centro Nacional de Referencia en Bacteriología, Instituto Costarricense de Investigación y Enseñanza en Nutrición y \\ Salud, Cartago, Costa Rica \\ 2 Centro de Investigación en Enfermedades Tropicales, Facultad de Microbiología, Universidad de Costa Rica, San \\ José, Costa Rica \\ 3 Área Rectora de Salud Oreamuno, Ministerio de Salud, Cartago, Costa Rica \\ 4 Área de Salud Oreamuno, Caja Costarricense de Seguro Social, Cartago, Costa Rica \\ 5 Dirección Regional Central Este, Ministerio de Salud, Cartago, Costa Rica. \\ * Correspondencia: fax: 506-2799852; ecampos@inciensa.sa.cr
}

Recibido 07-XI-2005. Corregido 13-IX-2006. Aceptado 01-II-2007.

\begin{abstract}
Prevalence of serum antibodies for the bacterium Brucella sp. in a tropical human population. Brucellosis is a systemic bacterial disease that can last years if not treated properly. The laboratory diagnosis is made by serological tests or isolation of the agent. We studied the prevalence of antibodies against Brucella sp. in inhabitants of rural communities of Cartago, Costa Rica, who are dedicated mainly to dairy cattle activities. We analyzed 714 representative samples with the Rose Bengal plate agglutination test (RBT) and the standard agglutination test in microplate (SAT). The overall prevalence was $0.87 \%$. No seroconversion was demonstrated for seropositive individuals. Even though $71 \%$ of the population mentioned consuming non-pasteurized milk, no statistically significant association was found (1.09\%, IC 0.30-2.77) between milk consumption and the presence of antibodies suggestive of infection by Brucella sp. As a brucellosis high-risk population, the absence of symptoms in the population agrees with the observed titers of antibodies, suggesting a low previous exposure to the agent. Rev. Biol. Trop. 55 (2): 385-391. Epub 2007 June, 29.
\end{abstract}

Key words: Brucella, human brucellosis, serology, Rose Bengal test, diagnosis.

La brucelosis, fiebre de Malta o fiebre del Mediterráneo, es una enfermedad causada por diferentes especies del género Brucella (B. melitensis, B. abortus, B. suis y B. canis) (Shapiro y Wong 1999). El cuadro clínico es generalizado, de comienzo agudo o insidioso, caracterizado por fiebre continua, intermitente o irregular, de duración variable, cefalea, debilidad, sudor profuso, escalofríos, artralgias, depresión, pérdida de peso y malestar general. Ocasionalmente surgen infecciones localizadas supurativas de órganos, incluyendo el hígado y el bazo. También se han documentado cuadros subclínicos e infecciones crónicas localizadas
(Chin 2001, Sauret y Vilissova 2002). El reservorio de la infección humana lo constituye principalmente el ganado vacuno, porcino, caprino y ovino, aunque se han dado casos por el contacto con perros. El riesgo de contraer esta zoonosis es principalmente ocupacional, siendo los peones de ganadería, granjeros, veterinarios y los trabajadores de mataderos los más expuestos (Corbel 1997, Chin 2001). La brucelosis se transmite por dos mecanismos claramente definidos: el contacto directo con materiales infectados como sangre o secreciones animales, y en forma indirecta, a través de la ingestión de leche o productos lácteos no pasteurizados (Chin 2001). 
En América Central la prevalencia de brucelosis bovina se ha estimado en un 4 a 8 $\%$ con una tasa de infección en lecherías que oscila entre 10 y $25 \%$, siendo Costa Rica y Guatemala los países más afectados (Moreno 2002). La brucelosis humana es una enfermedad de notificación obligatoria en Costa Rica; sin embargo, se considera que existe un subregistro importante de la enfermedad, debido a las dificultades diagnósticas, tanto clínicas como de laboratorio. En los últimos años, el número de casos notificados ha sido variable, observándose un aumento a partir del 2001 (Ministerio de Salud 2002).

El diagnóstico de laboratorio de la brucelosis se establece con el aislamiento del agente infeccioso o mediante pruebas serológicas, útiles, especialmente, cuando se demuestra un incremento en el título de anticuerpos en sueros pareados (Shapiro y Wong 1999). Durante las fases aguda y crónica de la enfermedad, se producen distintas clases de inmunoglobulinas y el cambio en los títulos se refleja en la reactividad de los anticuerpos en la prueba (Díaz 2002). La detección de IgM en pacientes con infección aguda puede ser de gran utilidad, ya que al momento de la hospitalización, un $94 \%$ de los casos presenta niveles detectables de éstos anticuerpos (Ariza et al. 1992). Los anticuerpos $\mathrm{IgM}$ disminuyen más rápidamente que los IgG e IgA, y aproximadamente $85 \%$ de los pacientes poseen altos títulos de $\operatorname{IgA}$ e $\operatorname{IgG}$ 18 meses después de la recuperación clínica (Ariza et al. 1992).

En los últimos años se ha informado un aumento de casos de brucelosis humana en zonas rurales de Cartago (principalmente de los distritos de Santa Rosa y Potrero Cerrado de Oreamuno), donde las principales actividades productivas son la ganadería de leche y la agricultura, y que son endémicas para brucelosis bovina según el Ministerio de Agricultura y Ganadería (R. Marín, com. pers.).

El objetivo de esta investigación es determinar la prevalencia de anticuerpos séricos contra Brucella sp. en habitantes de comunidades rurales lecheras de Cartago con el fin de conocer el grado de exposición real a este agente.

\section{MATERIALES Y MÉTODOS}

Población de estudio: Se realizó una encuesta transversal a todos los residentes mayores de cinco años en cada una de las viviendas seleccionadas de los distritos de Potrero Cerrado y Santa Rosa, del cantón de Oreamuno, Cartago, y que aceptó participar voluntariamente en el estudio llenando la fórmula de consentimiento informado. Se tomó una muestra representativa de la población de cada distrito (Instituto Nacional de Estadísticas y Censos 2003), seleccionando al azar conglomerados de 10 viviendas cada uno (listados de habitantes y ubicación de las viviendas del Programa de Atención Primaria en Salud, Región Central Sur, CCSS). Se cubrió de esta manera, el $10 \%$ de las viviendas de cada distrito. De acuerdo con esta técnica se seleccionaron, en total, 80 viviendas en Potrero Cerrado y 160 en Santa Rosa, para un total aproximado de 720 individuos a muestrear (asumiendo tres individuos mayores de cinco años por vivienda). El muestreo se realizó entre los meses de junio a diciembre de 2003. Las muestras fueron trasladadas al laboratorio donde se centrifugaron para separar el suero y se guardaron en congelación bajo la custodia del Centro Nacional de Referencia en Bacteriología, INCIENSA.

Pruebas serológicas: Las muestras de suero fueron analizadas mediante la técnica de aglutinación de Rosa Bengala en lámina (RBT) (Díaz y Moriyón 1989) y la prueba de aglutinación en microplaca (SAT, Serum Agglutination Test) (Alton et al. 1988) para determinar los títulos de anticuerpos (IgM e IgG). En la RBT, una suspensión de células de $B$. abortus teñidas con el colorante Rosa Bengala en buffer, $\mathrm{pH} 3.6$, constituyen el antígeno de la prueba, permitiendo detectar los anticuerpos específicos en el suero de los individuos muestreados (Shapiro y Wong 1999). Este estudio consideró un título $\geq 1: 4$ como significativo de infección previa con la bacteria.

En la técnica de SAT se hicieron diluciones del suero por analizar en buffer de fosfatos (PBS), pH 7.4, en una placa de 96 hoyos con 
fondo en "U". Se preparó una dilución 1:50 en PBS del antígeno RBT y se agregó a cada hoyo un volumen para obtener diluciones finales desde 1:10 hasta 1:320. Después de incubar en cámara húmeda a $37^{\circ} \mathrm{C}$ por $24 \mathrm{~h}$, se consideró un título $\geq 1: 80$ como significativo de exposición previa a Brucella sp. Aquellos sueros con títulos de anticuerpos $\geq 1: 80$ se analizaron, además, con la técnica de microaglutinación en placa más una solución de 2-mercaptoetanol al $0.1 \mathrm{M}$ para estimar el título de anticuerpos IgM (Alton et al. 1988).

Análisis de datos: La información recolectada en la ficha de investigación y los resultados de laboratorio se digitaron en una base de datos en Excel (Microsoft Office XP). Se realizó un análisis descriptivo de las variables que caracterizan a la población estudiada. Se hizo el cálculo de prevalencia de anticuerpos contra Brucella sp. y de los intervalos de confianza con ayuda del programa Epi Info (OMS). La población seropositiva se caracterizó de acuerdo con el sexo, edad, presencia de síntomas, ocupación, tipo de exposición y distrito de residencia.

\section{RESULTADOS}

De las 720 muestras planeadas en el diseño aleatorio para la encuesta seroepidemiológica, se obtuvo un porcentaje de respuesta del 80 \% (576/720) para los distritos de Santa Rosa y Potrero Cerrado. La prevalencia de anticuerpos séricos contra Brucella sp. obtenida en los habitantes de los distritos de Potrero Cerrado y Santa Rosa de Oreamuno, entre junio a diciembre del 2003, fue menor del $1 \%(0.87$ $\%)$, lo que corresponde a ocho por cada 1000 habitantes de la zona.

Las características de la población encuestada se resumen en el Cuadro 1. De cinco individuos que presentaron títulos de anticuerpos que sugerían exposición previa a Brucella sp. (títulos $\geq 1: 80$ ), todos eran hombres: dos peones agrícolas de 33 y 48 años, un peón de ganadería de 43 años, un estudiante de 11 años y un pensionado de 76 años. A pesar de que la diferencia no es estadísticamente significativa, se observa una tendencia de mayor seropositividad en hombres que en mujeres. Dado que los intervalos de confianza al $95 \%$ se traslapan en las diferentes categorías, se asume que no existe diferencia entre los distintos grupos etarios u ocupaciones descritas. Los resultados mediante la técnica de aglutinación Rosa de Bengala en lámina, concuerdan, en su mayoría, con los obtenidos por la técnica de microaglutinación en placa. Para los cinco seropositivos mencionados, únicamente en un caso se obtuvo un título menor al punto de corte establecido para la técnica en lámina (título 4 por RBT y 80 por SAT). De forma similar, no se observó una diferencia significativa en la prevalencia de anticuerpos contra Brucella sp. en las diferentes localidades investigadas (Cuadro 2). En ninguna de las personas seropositivas se demostró seroconversión (muestras tomadas con más de 30 días de diferencia), lo cual indica que no se trataba de una infección activa en ninguno de los casos.

$\mathrm{Al}$ analizar el recordatorio sobre la ingesta de productos lácteos se encontró que el $71 \%$ de la población refirió consumir leche no pasteurizada, sin embargo el porcentaje de positividad se mantuvo bajo (1.09\%) y no se observó diferencia significativa con el grupo de personas que consume lácteos pasteurizados (Cuadro 3). Por otro lado, al analizar el contacto con fluidos bovinos se observó que el $5 \%$ de los individuos que refirieron este antecedente, presentó títulos elevados, aunque no significativamente. Esto sugiere ser un factor asociado con la infección por Brucella sp., lo cual ha sido demostrado en estudios anteriores con grupos de riesgo (Campos et al. 1984).

En cuanto a la presencia de sintomatología característica de la enfermedad en la población, sólo uno de los cinco seropositivos refirió dolor en la rodilla, mientras que un porcentaje relativamente mayor de individuos refirió dolores articulares o fiebre en los últimos dos años (37 \% y $8.7 \%$, respectivamente). Asimismo, ninguna de las personas entrevistadas mostró una clínica compatible con un cuadro agudo de brucelosis. Esto se confirmó en parte por 
CUADRO 1

Características y seropositividad de la población encuestada en Santa Rosa y Potrero Cerrado de Oreamuno, Cartago

TABLE 1

Characteristics and seropositivity of the population surveyed in Santa Rosa and Potrero Cerrado, Oreamuno, Cartago

Variables

$$
\mathrm{N}
$$

Población encuestada

$$
\%
$$

IC $95 \%$

51.56-59.83

Femenino

Masculino

$$
321
$$

255

56

44

40.17-48.44

11.98

12.50

9.20

15-19

20-59

$\geq 60$

Desconocido

\section{Ocupación}

Estudiante

207

Peón agrícola/ganadería

Desconocido/desocupado

107

Pensionado

Operario

Comerciante

Otros*
35.94

24.31

140

18.58

6.77

39

19

3.30

18

3.12

2.08

5.90

55.21

10.24

0.87

12

34
9.44-14.91

$9.91-15.48$

$6.97-11.86$

51.04-59.32

7.88-13.01

$0.28-2.01$

$32.01-40.00$

20.85-28,02

15.48-21.99

4.86-9.14

1.99-5.10

$1.86-4.89$

108-3.61

4.12-8.15
Seropositivos

(\%)

IC $95 \%$
$(\%)$

0

$5 \quad 1.96$

$0.64-4.52$
1.39

$0 ., 94$

1.69

$0.04-9.08$

0

\section{.}


CUADRO 2

Distribución de individuos encuestados según localidad y de acuerdo con el título de anticuerpos contra Brucella sp.

TABLE 2

Distribution of individuals surveyed according to locality and in agreement with the titer of antibodies against Brucella sp.

\begin{tabular}{|c|c|c|c|c|c|c|c|c|}
\hline \multirow{2}{*}{ Localidad } & \multirow{2}{*}{$\begin{array}{c}\text { Total } \\
\mathrm{N}\end{array}$} & \multicolumn{4}{|c|}{$\begin{array}{l}\text { Número de individuos según título de } \\
\text { anticuerpos contra Brucella sp. }\end{array}$} & \multicolumn{3}{|c|}{ Seropositivos } \\
\hline & & $<40$ & 80 & 160 & 320 & $\mathrm{~N}$ & $\%$ & IC $95 \%$ \\
\hline Potrero Cerrado & 156 & 154 & 0 & 1 & 1 & 2 & 1.28 & $0.16-4.55$ \\
\hline San Juan de Chicuá & 144 & 143 & 1 & 0 & 0 & 1 & 0.69 & $0.00-3.81$ \\
\hline San Gerardo de Oreamuno & 165 & 165 & 0 & 0 & 0 & 0 & - & - \\
\hline Santa Rosa & 111 & 109 & 1 & 1 & 0 & 2 & 1.80 & $0.22-6.36$ \\
\hline Total & 576 & 571 & 2 & 2 & 1 & 5 & 0.87 & $0.28-2.01$ \\
\hline
\end{tabular}

CUADRO 3

Distribución de los individuos seropositivos de acuerdo con su exposición a factores de riesgo para la infección por Brucella $s p$.

TABLE 3

Distribution of the seropositive individuals according to their exposure to risk factors for infection by Brucella sp.

Factor de riesgo

Consumo de leche no pasteurizada $\uparrow$
Total

$\begin{array}{ccccc}\text { si } & 366 & 4 & 1.09 & 0.30-2.77 \\ \text { no } & 149 & 1 & 0.67 & 0.00-3,68 \\ & 515^{*} & 5 & 0.97 & 0.32-2.25\end{array}$

Total

Contacto con fluidos bovinos

$\begin{array}{ll}\text { si } & 40 \\ \text { no } & 536\end{array}$

576
Seropositivos

$\% \quad$ IC $95 \%$

$\mathrm{N} \quad$ IC $95 \%$

$0.61-16.92$

$0.11-1.63$

$0.28-2.01$

† La leche no pasteurizada proviene de producción propia.

* Se eliminó 61 individuos porque no precisaban el dato de consumo.

\$ Incluye: abortos, retenciones de placenta, descargas vaginales, partos complicados.

zona norte de Cartago, donde la principal actividad de producción es la agricultura y la ganadería de leche. Esta es una zona de alta prevalencia de brucelosis bovina, por lo que sus pobladores poseen un mayor riesgo de exposición a Brucella sp., ya sea de tipo laboral o por el consumo de productos lácteos no pasteurizados. En vista que no se observó diferencias significativas en la prevalencia de anticuerpos en pobladores de las distintas localidades, se podría asumir que en otras regiones con características similares la prevalencia sea igualmente baja.

En un estudio realizado por Campos et al. en 1984, se informa una diferencia significativa entre la prevalencia de anticuerpos contra 
Brucella sp. en poblaciones de riesgo ocupacional (asistentes de veterinarios, veterinarios, inseminadores, trabajadores de laboratorio) y poblaciones sin riesgo. Para esta población de riesgo se encontró un $50 \%$ de seropositividad, por lo que en un estudio realizado en población general cabe esperar que la prevalencia sea mucho más baja.

Si existiera una mayor coincidencia con el trabajo de Campos et al., debería esperarse una seropositividad cerca del $9 \%$ en el grupo de mayor riesgo del presente estudio. Sin embargo, en la población estudiada que informó una ocupación de peón agrícola o ganadero, la prevalencia informada fue de $2.80 \%$. La baja seropositividad en este grupo podría explicarse, en parte, por el mejoramiento de las prácticas de manejo de ganado bovino en nuestro país (Moreno 2002).

De acuerdo con lo descrito en la literatura, el consumo de lácteos no pasteurizados continúa siendo una de las principales causas de infección (Corbel 1997). A pesar de que en el área estudiada la práctica de consumir leche no pasteurizada es alta, el riesgo de infección en esta población pudo ser menor, pues según lo manifestado por muchos de ellos, tienen prácticas como hervir la leche antes de consumirla, medida que evita la infección por Brucella sp. $\mathrm{y}$ otros agentes microbianos presentes en los alimentos lácteos crudos.

La brucelosis es una enfermedad en la cual un espectro de síntomas inespecíficos aparece alrededor de dos semanas después de la infección. Algunos de los signos y síntomas más comunes de la enfermedad son: cefalea, fatiga, fiebre, mialgia, sudoración y pérdida de peso (Sauret y Vilissova 2002). La ausencia de síntomas en la población, al momento de realizar la encuesta, concuerda con los bajos títulos de exposición observados. En vista de que la brucelosis puede cursar con sintomatología muy inespecífica, y con el fin de racionalizar los recursos de laboratorio para el diagnóstico de la enfermedad, habría que tomar en cuenta la sintomatología en conjunto con la exposición a factores de riesgo como el consumo de lácteos no pasteurizados y/o el contacto con fluidos animales.

Las técnicas de aglutinación Rosa de Bengala y SAT son ampliamente utilizadas en el diagnóstico de la brucelosis humana porque poseen alta sensibilidad, son fáciles y rápidas así como de bajo costo (Serra y Viñas 2004). Debido a que las pruebas serológicas no están estandarizadas, cada laboratorio debe establecer sus propios puntos de corte basados en las metodologías utilizadas. Por lo general, son pruebas que funcionan bastante bien para establecer el diagnóstico en pacientes con infecciones primarias, mientras que en pacientes con contacto previo o de zonas endémicas, se debe considerar títulos de exposición más elevados (Ruiz-Meza et al. 2005). Mediante la combinación de estas técnicas es posible establecer un diagnóstico definitivo de la enfermedad al determinar niveles altos de anticuerpos específicos o seroconversión.

Los síndromes febriles de foco no aparente son una causa importante de afecciones en nuestro país, por lo cual, es recomendable evaluar las técnicas empleadas para el diagnóstico de brucelosis en los establecimientos de salud, y se proponga la utilización de técnicas más específicas y sensibles, como las utilizadas en este estudio, que permitan obtener un resultado de mayor confiabilidad.

\section{AGRADECIMIENTOS}

Este proyecto se realizó con fondos del INCIENSA (FODESAF), Caja Costarricense de Seguro Social, Ministerio de Salud y recibió apoyo financiero por parte del Consejo Nacional para Investigaciones Científicas y Tecnológicas (CONICIT) y de la Vicerrectoría de Investigación de la Universidad de Costa Rica. Se agradece a Edgardo Moreno, Escuela de Medicina Veterinaria de la Universidad Nacional por la donación del antígeno, a Hilda Bolaños por la revisión del artículo y a Carlos Raabe por su colaboración en el análisis estadístico. 


\section{RESUMEN}

La brucelosis es una enfermedad bacteriana generalizada con tendencia a la cronicidad si no se trata adecuadamente. El diagnóstico de laboratorio se realiza por el aislamiento e identificación del agente o en la mayoría de los casos mediante pruebas serológicas. En este estudio se informa la prevalencia de anticuerpos séricos contra Brucella sp. en habitantes de comunidades rurales de Cartago dedicadas principalmente a la ganadería de leche. Se analizó un total de 714 muestras representativas de la población mediante la técnica de aglutinación Rosa de Bengala en lámina (RBT) y la prueba de aglutinación en microplaca (SAT). Se encontró una prevalencia de 0.87 $\%$, y en ninguna persona seropositiva se demostró seroconversión. Aún, cuando el $71 \%$ de la población refirió consumir leche no pasteurizada, no se encontró asociación estadísticamente significativa (1.09\%, IC 0.30-2.77) entre el consumo de leche no pasteurizada y la presencia de anticuerpos sugestivos de infección por Brucella sp. A pesar de ser una zona de alta prevalencia de brucelosis bovina por Brucella abortus, la ausencia de síntomas en la población y los bajos títulos de anticuerpos observados sugieren una escasa exposición previa al agente.

Palabras clave: Brucella, brucelosis en humanos, serología, diagnóstico, prueba con rojo de Bengala.

\section{REFERENCIAS}

Alton, G.G., L. M. Jones, R. D. Angus \& J. M. Verger (ed.). 1988. Techniques for the brucellosis laboratory. Institut National de la Recherche Agronomique, Paris, Francia.

Ariza, J., T. Pellicer, R. Pallares, A. Foz \& F. Gudiol. 1992. Specific antibody profile in human brucellosis. Clin. Infect. Dis. 14: 131-140.

Campos, E., G. Vicente, J.A. Ramírez, \& E. Moreno. 1984. Evaluación seroepidemiológica de la brucelosis humana en poblaciones de riesgo ocupacional. Acta Med. Cost. 47: 8-9.

Corbel, M.J. 1997. Brucellosis: an overview. Emerg. Infect. Dis. 3: $213-221$.
Chin, J. 2001. El Control de las Enfermedades Transmisibles. Publicación Científica y Técnica No. 581, Washington DC, EEUU.

Díaz, R. \& I. Moriyón. 1989. Brucellosis, Clinical and laboratory aspectsp, p. 73-83. In E.J.Young \& M.J. Corbel (eds.). Laboratory techniques in the diagnosis of human brucellosis. CRS, Boca Ratón, Florida, EEUU.

Díaz, R. 2002. Serological Diagnosis of Human Brucellosis. Seminario Avanzado Brucelosis Humana y Animal, Pamplona, España.

Godfroid, J., A. Cloeckaert, J.P. Liautard, S. Kohler, D. Fretin, K. Walravens, B. Garin-Bastuji \& J.J. Letesson. 2005. From the discovery of the Malta fever's agent to the discovery of a marine mammal reservoir, brucellosis has continuously been a reemerging zoonosis. Vet. Res. 36: 313-326.

Instituto Nacional de Estadísticas y Censos. 2003. Población total por sexo, según años calendario 2000-2010. Cuadro 4. INEC, San José, Costa Rica.

Ministerio de Salud. 2002. Casos Registrados de Enfermedad de Declaración Obligatoria según causa específica por año de presencia. Costa Rica 20002002. Ministerio de Salud, San José, Costa Rica.

Moreno, E. 2002. Brucelosis in Central America. Vet. Microbiol. 90: 31-38.

Ruiz-Meza, J.D., J. Sánchez-Gonzalez, J.M. Reguera, L. Martín, S. Lopez-Palmero \& J.D. Colmenero. 2005. Rose Bengal test: diagnostic yield and use for the rapid diagnosis of human brucellosis in emergency departments in endemic areas. Clin. Microbiol. Infect. 11: 221-225.

Sauret, J.M. \& N. Vilissova. 2002. Human brucellosis. J. Am. Board Fam. Pract. 15: 401-406.

Serra, J. \& M. Viñas. 2004. Laboratory diagnosis of brucellosis in a rural endemic area in northeastern Spain. Int. Microbiol. 7: 53-58.

Shapiro, D. \& J. Wong. 1999. Brucella. p. 625-631. In P.R. Murray, E. Baron, M. Pfaller, F. Tenover \& R. Yolken (eds.). Manual of Clinical Microbiology. ASM, Washington DC, EEUU. 
